\title{
FLUID RETENTION SYNDROME (FRS) - A REVIEW
}

\author{
ZAMANU GKMS ${ }^{1}$, HOSSAIN A $^{2}$, MONDOL BA ${ }^{3}$, HOSSAIN SS $^{4}, \mathrm{DEB} \mathrm{SR}^{5}$
}

\begin{abstract}
Summary:
Fluid retention syndrome is a poorly understood disorder occurring predominantly in women of reproductive age in which excessive body fluid is retained without cardiac, hepatic, renal, allergic or protein loosing diseases.

The presence of oedema implies an increase in extracellular fluid and its principal constituents, sodium and chloride. Most individual may be expected to gain 0.5 to $1.4 \mathrm{Kg}$ (1-3 lb.) weight during the day, with a subsequent return to the previous morning's weight after a night's rest. Patients who retain fluid excessively will, in general, gain more than !. $4 \mathrm{KS}$. (3 lb.) Daily and if this continues, clinical oedema will eventually develop'.

FRS occurs almost exclusively in women. Edema is worst after the end of the day's activity and aggravated by spending long hours in upright posture. The cardinal symptoms are swelling and bloating of the feet, the ankels, the legs, the abdomen and it is often noticed in eyelids, the face and sometimes the breast towards the end of the day. Psychiatric symptoms are frequent accompaniment of FRS. They are rqnges from fatigue, irritability, anxiety and depression to symptoms of severe depressive illness.
\end{abstract}

Key words: Fluid retention syndrome, extracellular fluid, oedema

J Dhaka Med Coll. 2011; 20(1) : 97-108.

\section{Introduction:}

The commonly used term for the fluid retention syndrome, 'Cyclical Oedema', 'periodic swelling' are misleading. Because many thousands of twice-daily body weight measurements on patients with idiopathic oedema made the past 25 years have shown that recurring bouts of oedema formation and dissipation only very rarely show sufficient regularity to warrant use of the terms 'cycle' or 'periodic' oedema, which are there fore inaccurate, and best avoided $^{2}$. The term idiopathic oedema is misleading because sufferers rarely show pitting or dependent oedema and contributory risk factors can be defined that render the term "idiopathic" redundant. The descriptive term "fluid retention syndrome' is more accurate, as it embodies the view that the condition has a multifactorial aetiology'.

The central role of fluid retention syndrome is the capillary functional abnormality leading to increase' capillary permeabilily, oozing fluid and protein out of capillary, decrease circ4latory blood volume, decrease renal blood flow with the secondary role of renal influences (Fall in GFR, increase renin secretion, angiotensin-Il production, hyperaldosteronism, probable hypervasopressinism, and excessive orthostatic fall in' renal dopamine) which are thought to act by replenishing the reduced plasma volume and in this way maintain capillary hydrostatic pressure so that transudation can continue and edema increase while orthostatic persists.

In establishing a diagnosis of fluid retention syndrome, three considerations are critical.

1. The demonstration of excessive weight gain or fluid retention.

2. The exclusion of organic disease known to predispose to oedema formation.

3. Evidence of substantial psychological or emotional" disturbance.

Management of FRS' Directed at relieving the underlying emotional difficulties, dietary control calorie intake, reduced salt and fluid intake, 'external compression of limbs, swimming and muscular exercise, diuretics

1. Dr. Gazi Khan Md. Shahiduzzaman Assistant Professor of Medicine, Khulna Medical College, Khulna

2. Dr. Amir Hossain, Assistant Professor of Medicine, Khulna Medical College, Khulna

3. Dr. Badrul Alam Mondol, Associate Professor of Neurology, Dhaka Medical College, Dhaka.

4. Dr. Sheikh Shahinoor Hossain, Assistant Professor, Department of Respiratory Medicine, Dhaka Medical College, Dhaka

5. Dr. Sudip Ranjan Deb, RP, Dhaka Medical College, Dhaka

6. Dr. Syed Razaul Huq, Assistant Professor, Respiratory Medicine, NIDCH, Dhaka

Correspondence: Dr. Gazi Khan Md. Shahiduzzaman, Assistant Professor of Medicine (C.C), Khulna Medical College, Khulna 
mostly thiazide and angiotensin converting enzyme inhibitor like captopril are good drug to reduce the water and sodium volume.

Fluid Retention Syndrome (FRS) is a disorder or a group of disorders that is diagnosed by exclusion of the many known types of excessive fluid retention. These include such common conditions as congestive heart failure, kidney disease of the nephrotic and renal insufficiency types, hepatic cirrhosis with ascites and venous and lymphatic obstruction. Oedema may also occur in protein malnutrition, various allergic, and inflammatory states, hypothyroidism, Lryperthyroidism, hypoprotinaemia,

hype rcoftisolism, anaemia and hypertension. When thephysicianhas considered'and excludedall of these and other known causes of oedema, his patient may be said to have idiopathic oedema.

Obesity increases the predisposition to fluid retention syndrome (FRS). The retention of sodium and water is usually associated with increased nervousness and irritability and in more severe cases with headache and nausea. Patients with the more serious and persistent form of the syndrome often exhibit deep seated psychogenic disturbance. These abnormalities may be overlooked or minimized by the physician during the initial examination if his attention is focused on uncovering serious organic disease $\mathrm{e}^{4}$.

\section{Pathophysiology.}

Inappropriate response to upright posture ${ }^{5}$

In a great majority of patients there is an evident postural component in the development of the oedema ${ }^{5}$. The oedema is relieved when the patient lies down. The weight measurements taken in the morning on rising and again in the evening on retiring, show a gain of weight greater than the physiological weight of 1 to $3 \mathrm{Ib}^{1}$ and reflect the effect of upright posture. Only in several cases and those are in a minority-the normal release of sodium and water during recumbence fail, leading to persistent and cumulative retention of sodium and water and to generalized oedema.

The physiological adaptation to upright posture involves several haemodynamic and hormonal changes. The change from recumbency to
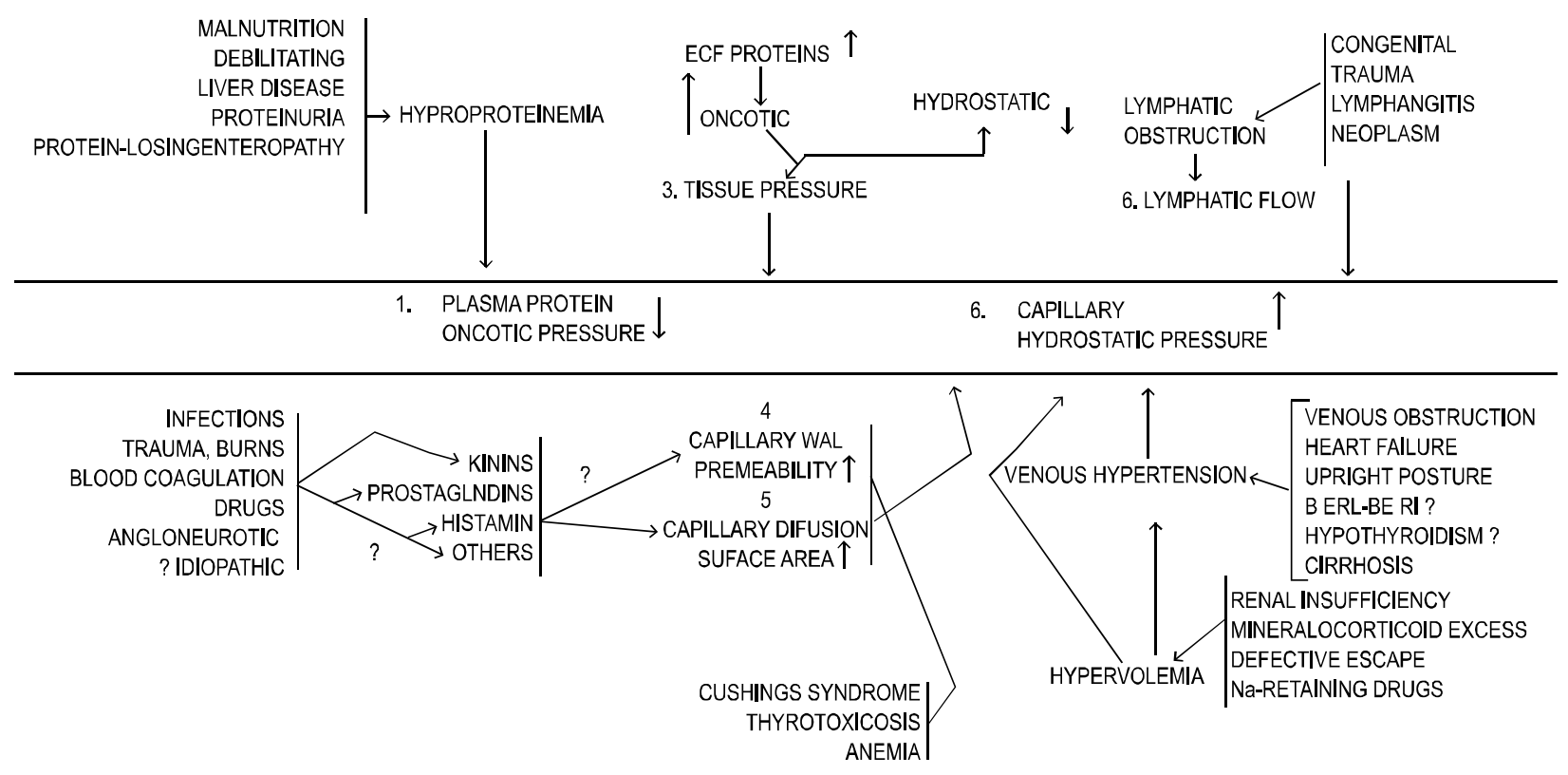

Fig.-1: Primary mechanism in the pathogenesis of fluid retention. Since all mechanism result in leakage of fluid from the vascular into the extravascular space the extent of cedema would be limited by the fall in blood pressure with developing hypovolemia where it not for secondary mechanism (not depicted) which result in renal retention of Na and water e.g. secondary adolteronism possible vaopressin release and renal changes (e.g. fal in GFR). 
upright posture results in the pooling of blood below the heart, which leads a decrease in venous return and a decrease in cardiac output. The autonomic nervous system responds with an instantaneous increase in sympathetic activity, which leads to cardioacceleration, vasoconstriction and increased myocardial contractility resulting in increased cardiac output, In addition the increased sympathetic activity results in increased peripheral resistance and the increase in cardiac output. Combines to maintain the arterial blood pressure.

Meanwhile, other more sluggish mechanism come into play to expand the extra cellular fluid volume and thus support the blood pressure is yet another way.

In response to upright posture there is and increased production of renin by the kidney. One possible explanation is that the increase in renin is consequent to a decrease in renal blood flow in the upright position ${ }^{6}$. There is a good evidence that the increase in renin induced by upright posture is closely associated with and dependent on the sympathetic discharge. Renin catalyses the formation of Angiotensin-II. Angiotensin-II In addition to elevating blood pressure directly, stimulates adrenocortical sceretion of aldosterone. The decrease in the meabolic clearance rate of aldosterone due to a lower hepatic blood flow in upright contributes to the physiological hyperaldosteronism to a lesser degree ${ }^{8}$. Aldosterone promotes sodium retention. An early stage of postural adaptation is characterised by the stimulation of the secretion of the antidiuretic hormone (ADH), a factor contributing to the reduction of urine volume during the first 30 minutes after assuming upright posture ${ }^{9}$. In a time gap between the rapid-acting catecholamine response and a slower acting alodosterone induced sodium retention. This leads to expansion of extracellular volume and supports the arterial blood pressure on upright posture.

This description of the physiology of postural adaptation implies that many factors involved in the pathogenesis of idiopathic oedema may be operative in the course of postural adaptation. The assuming of upright posture may lead to the minifestation of a hidden failure not evident during recumbency. Thus upright posture play the role of a precipitationg factor. Leading to maninfestation of oedema by an exaggerated response on any level of the system.

\section{Postural venous plasma pooling ${ }^{10}$}

In fluid retention syndrome the change from recumbency to upright posture results in the pooling of blood within the intravascular space. In the absence of visible varicosities the pooling is presumed to be limited predominantly to the deep veins. Possible explanations for such intravascular blood volume pooling with erect posture include.

a. An inherent abnormality of vascular smooth muscles.

b. Abnormal peripheral vascular adrenergic nervous intervation responsiveness.

c. A decreased or absent vascular response to circulating hormones, the most important of which probably norepinephrine.

This excessive blood volume pooling in the lower parts of the body lead to excessive reduction in renal blood flow and glomerular filtration rate and hyperaldosteronaemia. Consequent retention of salt and water with increase in plasma volume and dependent oedema ensues.

\section{Capillary wall permeability and capillary diffusion surface area.}

Among the pathogenic factors related to formation of oedema, changes in the capillary wall permeability and changes in the capillary diffusion area, probably due to excessive dilatation of precapillary sphincter appears to be important ${ }^{11}$. Permeability to protein appears to increase in response to bradykinin, histamine and other dilators of the precapillary sphincter, probably largely through the elevated capillary hydrostatic pressurethatresults ${ }^{12}$ and possibly in part through a direct action on the capillary wall ${ }^{13}$. There is also evidence that bradykinin increase the capillary and vascular surface area available for diffusion by reducing precapillary resistance and opening up larger numbers of capillaries to perfusionr 2 . These 
combined effects of kinins and other tissue hormones greatly increase transudation and cause oedema. Observations on five patients withhyperbradykininismr3have indicated that kinins might be involved in increasing the peripheral vascular pooling of blood in the upright posture and in causing the pitting or brawny oedema sometimes seen in this disorder. These all five patients almost invariably had plasma concentrations of bradykinin above the normal range and normal plasma kallikreinogen concentrations. However, plasma-bradykininase-1 activity was below the levels found in normal subjects, when the en $41 \mathrm{me}$ was measured in the plasmas of two patients out of five patients. Since there was a good negative correlation between plasma -bradikininase-1 and plasma bradykinin concentrations in samples obtained from two of the patients who were related, it seems likely that deficiency of circulating bradykininase-1 is the primary defect responsible for this patients with this disorder. Possible low levels of bradykininase activity in the lungs might also have been partly responsible for the accumulation excessive amounts of bradykinin in the plasma in these patients. Although there are no published measurements of plasma kinin concentration it patients with idiopathic oedema, many of the finding observed in the upright posture in these patients are very similar to those that would be expected to result from excessive peripheral action of bradykinin. The severe capillary protein leak described in occasional patients with idiopathic oedema, and sometimes associated with episodes of shockra would also be consistent with bouts of spontaneous release of large amount of kinin, through there is no direct evidence to support this possibility.

\section{Effect of posture on the metabolic clearance rate, plasma concentration and blood production rate of aldosterone in man.}

As one of the mechanism of orthostatic oedema,augmented activity of reninangiotensin-aldosterone system secondary to excessive, fluid transudation and a. subsequent fall in plasma volume is postulated ${ }^{5}$. Also effect of posture on aldosterone secretion and metabolism was studied ${ }^{8}$. After sitting there was no significant change of Metabolic Clearance Rate (MCR). The plasma concentration of aldosterone increased 6-fold and the blood production rate increased-fold.

After standing the plasma concentration of aldosterone increased 10-fold and the blood production rateincroasod.8-fold, and the MCR decreased significantly by 23Yo" Previously, Bogus et al. reported a 50\%odecreased MCR upon changing from supine to the upright positions. These changes are not significant in normal subject but more pronounced in patients of fluid retention syndrome.

\section{Hypoproteinemia}

Every patient with oedema of obscure origin should be checked for hypoproteinemia. When it is severe and associated with an obvious cause such as nephrosis, the oedema loses its idiopathic level. Mild hypoproteinemia associated with no recognizable cause has been considered to be the cause of idiopathic oedema by Gill et $\mathrm{al}^{16}$. Their observation showed a lowered concentration and total circulating pool of plasma albumin. These changes were attributed to a significantly accelerated movement of albumin from the intravascular compartment to an enlarged extra vascular pool. The finding of hypoproteinemia has not been confirmed 5,11,14,17 and, plasma volume has been found to be normal in other series of patients with idiopathic oedema ${ }^{11}$.

Although it may doubted that hypo albuminaemia is a general finding in patients with FRS, there' is good evidence that rapid leakage of protein from the circulating plasma compartment and hypovolumia occurs in occasional patients with what appears to be a rare, Special type of FRS associated with massive oedema and with shock like episodes of hypotensionra. In most patients with the commoner forms of idiopathic oedema however, plasma protein concentrations actually rise to an extent at least as great $(+10 \%)$ as in normal subjects during 4 hours in upright posture ${ }^{18}$, indicating that loss of protein from plasma into the interstitial space is usually no more rapid than in healthy individual.

\section{Evidence of capillary defect to produce FRS}

There is microanatomic and functional evidence of a capillary lesion in patients with 
FRS. Sims et al ${ }^{17}$ first showed that the basement membrane of capillaries in biopsy specimens from the gastrocnemius muscle was significantly thicker in 11 patients with FRS [4700+1900 A" (SD)] than in 7 normal control subjects $\left(2600+210 \mathrm{~A}^{0}, \mathrm{P}<0.05\right)$. They also found that 7 of their patients with FRS had family histories of diabetes mellitus, 3 had frankly diabetic glucose tolerance test andanother4 had abnormal cortisone-glucose tolerance tests. The findings suggested that the microangiopathy observed might be of the type seen in diabetes mellitus.

Coleman et $\mathrm{al}^{19}$ confirmed the thickening of capillary basement membranes in a patient with FRS and pointed out that such lesions have been demonstrated in many diseases, including polymyositis, systemic lupuserythomatosus, scleroderma, arteriosclerosis and diabetes mellitus. There are therefore, reasons for uncertainty about the specificity of the basement membrane thickening, as well as its pathogenic significance as the possible cause of increased capillary permeability to protein in patients with idiopathic oedema.

\section{Role of heat}

While many patients report that their oedema is worst in warm, humid weather, there are occasional patients in whom heat seems to be the predominant factor in the pathogenesis of oedema. One such patient was reported by Streeten DPH in 1960, in whom the excretion of sodium and water was clearly abnormal when she was other feet in hot environments but was entirely normal during prolonged standing in a room air conditioned to below $15^{\circ} \mathrm{c}$. Edwards and Bayliss ${ }^{9}$. have reported another patient, apparently of this type who was troubled with oedema while working in India but not in Britain. It is obviously important to be quiet sure that the presence of thyotoxic oedema has been ruled out in such patients. Presumably, there is an excessive dilatation of the precapillary sphincter in response to heat but not in response to standing in cool environment in those patients.

\section{Diuretic induced oedema ${ }^{20}$}

It has been postulated that in these patients, chronic diuretic administration leads to mild blood volume depletion which causes chronic hyperreninaemia and juxtraglomerular hyperplasia. Salt retaining meehanisms appear over compensated for the direct effects of diuretics 20.Acute withdrawal of the diuretics can then leave the sodium retaining forces unopposed, leading to fluid retention and oedema. When the frusemide was stopped, oedema became more severe for a few days, then rapidly diminished and disappearance by the end of 2-3 weeks.

\section{Compulsive salt intake and oedema ${ }^{21}$}

It has been postulated that in these patients, chronic diuretic administration leads to mild blood volume depletion which causes chronic hyperreninaemia and juxtraglomerular hyperplasia. Salt retaining meehanisms appear over compensated for the direct effects of diuretics 20.Acute withdrawal of the diuretics can then leave the sodium retaining forces unopposed, leading to fluid retention and oedema. When the frusemide was stopped, oedema became more severe for a few days, then rapidly diminished and disappearance by the end of 2-3 weeks.

\section{Compulsive salt intake and oedema ${ }^{21}$}

There is a high capacity to excrete an excessive salt load in man whatever may be the cause, if the water intake is sufficient to help to excrete the excessive salt. If excessive salt intake is not compensated for by a high water intake, sodium accumulates in the extra oellular fluid and can, be a rare cause of FRS. This oedema can be controlled by only restriction of salt intake.

\section{Female sex hormone}

It is well known that oestrogon and progesterone are capable of inducing sodium retention and that an appreciable number of normal women, particularly in obese retain increased quantities of sodium, chloride and water during the immediate pre-menstrual period. The maximum gain in weight is observed most frequently during the immediate pre-menstrualperiod.2obut may appear in mid cycle or following cessation of menstruation. The syndrome has been observed in postrnenopausal patients as well. To date it has 
not been possible to correlate excessive fluid retention in these patients with greater than normal oestrogen or progesterone excretion. The magnitude of salt and water retention is diminished but is not abolished by hysterectomy. Studies on a patient following bilateral oophorectomy failed to disclose significant cycles of sodium and chloridretention ${ }^{22}$.

The absence of cyclical oedema in female patients prior to the menarche and relative' rarity of syndrome in postmenopausal women suggest the importance of the cyclical changes in the female hormone secretion as a conditioning mechanism through which excessive retention of salt and water may occur.

\section{Hereditary periodic oedema ${ }^{23}$ :}

Hereditary periodic oedema and peritonitis was observed in a Swedish family traced back for 7 generations to the $17^{\text {th }}$ century. Seventeen members of the family had the disease. An analysis of pedigree confirmed that this disease is caused by an autosomal dominant gene.

Studies on the capillary permeability in the three patients of same family, confirmed that diluted analogous serum of patients with hereditary periodic oedema contains a factor increasiog capillary permeability.

The urinary 5-HIAA excretion was quite normal both during periods of oedema and during free intervals in all three patients.

\section{Summary of Pathogenesis of fluid retention syndrome.}

Figure 2 summarizes known and postulated steps in the pathogenesis of fluid retention of the orthostatic $\mathrm{Na}$ and water retaining types. the question marks indicate postulated factors that have not been shown to be present and factors that are present but have not been demonstrated to have the effects attributed to them.

Studies of the blood histamine in one patient showed low values during attacks of oedema. Consecutive 24 hour urinary histamine detrminations were performed during one month in the patients at the same time as the 5-IAA determinations. During attacks, there was a paronunced decrease in urinary histamine. Between attacks. Very high values were usually found. $\mathrm{C}^{14}$ histamine injected during on attack of oedema in one of the patients was excreted normally.

The present studies strongly indicate some error in the metabolism of histamine. The fact that exogenous histamine is metabolised in an apparently normal way may suggest on error in the formation of histamine or in the release of endogenously formed histamine.

The central role of the postulated capillary abnormality is evident, as is the secondary role of renal influences (fall in GFR, increase renin secretion, angiotensin-II production, hype raldosteronism, probable hypervasopressinism, and excessive orthostatic fall in renal dopamine) which are thought to act by replenishing the reduced plasma, volume and in this way maintain capillary drostatic pressure so that transudation can continue and edema i8ncrease while orthostasis persists.

\section{Presentation of Fluid Retention Syndrome:}

Age and, sex

Idiopathic oedema occurs almost exclusively in women. In females, the disorder, has never been reported before puberty, it usually continues or may first be observed after menupause $^{21}$.

\section{Periodicity}

In most women with FRS, a strong postural component in the pathogenesis is responsible for the predominantly diurnal periodicity. Oedema is worst after the end of the days activity' or the night's activities and a aggravated by spending long hours in the upright posture. It is also frequently more severe in hot weather. In some but not in all women there is superimposed premenstrual Aggravation of oedema.

\section{Features of fluid retention:}

The cardinal symptoms are swelling and bloating of the feet, the ankles, the legs, the abdomen and it is often noticed in eyelids, the face and sometimes the breast towards the end of the day. Patient often shows a striking diurnal increase in abdominal girth; finger 
swelling may necessitate removal of rings; and increase in lower limb volume may cause tightness of footware ${ }^{1}$. These patients show a weight gain during some days of at least $1.4 \mathrm{Kg}$ and in some cases diurnal weight increase may be as much as $6 \mathrm{Kg}^{1}$.

Abdominal swelling may increase so severely during the course of the day that a few women with idiopathic oedema find it necessary to change into a larger skirt in the afternoon. Oedema of the feet may be so severe that a patient who removes her shoes at 5 or 6 P.M. is unable to fit into them again an hour latter unless she has spent the hour recumbent. Due to swelling of abdomen these patients are frequently accused of being pregnant.

\section{Functional autonomic disturbance:}

Many fluid-retaining patients give a history suggesting Para sympathetic (cholinergic) hyper-reactivity of the bowel, bladder and vascular system ${ }^{3}$. A history of irritable bowel syndrome is common and patients may complain of intermittent diarrhea and constipation. Compliants of urge frequency of micturationa mounting to urge incontinence my develop.

\section{Affective psychiatric disorder:}

Psychiatric symptoms are a frequent accompaniment of fluid retention syndrome. These range from minor degrees of fatigue, irritability, anxiety and depression to symptoms of severe depressive illness. Affective symptoms form an integral part of fluid retention syndrome and the condition is a true psychosomatic disorder ${ }^{24}$. Other workers have reported the presence hysterical neurosis, psychotic illness and a wide range of personality abnormalities along with FRS. Some have suggested that symptoms may be worsened or precipitated by stressful life events ${ }^{25}$ and patients become irritable during the bouts of fluid retention ${ }^{26}$.

\section{Other features:}

Visual blurring caused by retinal oedema is common in fluid-retaining patients and may lead to patients to consult an ophthalmologist. In a few patients headaches are severe and worse in the morning, resembling the
Headache of increased intracranial pressure, presumably caused by a degree of cerebral oedema. Polydipsia results from hypovolaemic stimulus following the extravasation of fluid from the intravascular to extravascular compartments and leads to the consumption of large quantities of fluid with nocturnal polyuria. If thirst is intense the patient may be suspected of having diabetes mellitus (particularly as a family history of diabetes is common) or hysterical water drinking.

\section{Diagnosis of Fluid Retention Syndrome}

Idiopathic oedema is a common disorder that is diagnosed by the exclusion of cardiac, hepatic, renal, allergic and other systemic diseases.

\section{Diagnostic Procedures}

\section{Changes in body weight:}

It is useful in characterizing the syndrome to obtain accurate weight measurements in the morning. prior to breakfast and in the evening upon retiring. Patient who retain fluid excessively will, in general, again more than

$1.4 \mathrm{~K} \mathrm{~g}(3 \mathrm{Ib})$ daily and if this continues clinical oedema will eventually develop. The detection of excessive diumal weight gain is both a key to diagnosis as well as a very important means of monitoring therapy.

\section{Blood chemical measurement:}

Serum potassium and magnesium values are extremely important measurements for patients who have received prolonged diuretic therapy. Since many patients are often unaware of the nature of magnitude of their diuretic therapy, it is well to check serum uric acid and blood glucose as well as blood urea nitrogen levels.

Hypokalaemia in the presence of elevated serum uric acid level suggests excessive diuretic therapy despitea Negative history ${ }^{1}$.

\section{Test for Renal, Hepatic and Cardiac function:}

\section{Renal function}

These tests include urinalysis, including sediment and specific gravity, phenosulfonphthalein test, serum Electrolytes, urea, 
creatinine, creatinine clearance rate, urinary total protein and renal biopsy in doubtful cases.

\section{Hepatic function:}

Studies for hepatic function include enzyme analyses and serum bilirubin value, viral markers, X-ray film for oesophageal varices, endoscopy of upper gastrointestinal tract, ultrasonography of HBS and liver biopsy in doubtful cases.

\section{Cardiac function:}

Electrocardiogram (ECG), chest X-ray film are taken, and venous pressure and circulation time are recorded.

Echocardiograpy, cardiac catheterisation are done if needed

\section{Plasma protein studies:}

Serum albumin and globulin levels should be determined with electrophoretic studies.

Thyroid function test:

T3 T4 TSH, RAIU, Scanning are done in appropriate cases.

\section{Glucose tolerance test:}

1. Oral glucose tolerance test

2. Cortisone glucose tolerance test.

\section{Water excretion test}

\section{In Horizontal Position}

This is carried out in the morning under fasting conditions. Smoking must be excluded. Test: 500 $\mathrm{ml}$. of water is ingested at $8 \mathrm{AM}, 8: 15$ and 8:30 (total'1500 ml.). The patient voids at 8:30 and discards this specimen. Urine volume is then measured hourly for the subsequent four hours. The maximum volume attained in any single hour is measured as well as the total percentage of ingested water which is excreted. Most normal subjects will attain a volume of at least $300 \mathrm{ml}$ or more in one hour and a total of at least $80 \%$ to 90 Yo in the four hours period. The majority of patients with FRS without underlying organic disease, will exhibit a-normal water excretion level in the horizontal position.

\section{In upright position:}

If water excretion is normal in the horizontal position, then the same test should be repeated the following morning with the patient up and about the entire fourh our period. The difference in the rate of water excretion in this position as compared to that in the horizontal position will give an overall indication in a particular, patient of importance of posture in facilitating salt and water retention.

\section{Psychiatric interview:}

Evaluation of the patient's psychological and emotional status is essential in establishing the diagnosis of-FRS. Furthermore, such an interview is most helpful in organizing the patient's overall therapeutic program.

\section{Summary of diagnosis:}

In establishing a diagnosis of fluid retention syndrome, three consideration are critical.

1. The demonstration of excessive weight gain or fluid retention.

2. The exclusion of organic disease known to predispose to oedema forr4ation.

3. Evidence of substantial psychological or emotional disturbance.

\section{Management of Fluid Retention Syndrome ${ }^{26}$} General consideration

Therapy must be directed at relieving the underlying emotional difficulties as well as correcting the excessive fluid retention. The loss of oedema alone can scarcely be accepted to relieve symptoms significantly when an excess fluid retention resulted from a fundamental psychological disturbance. Loss of oedema fluid may improve physical comfort to some extent and may reduce overall irritability, but the physician cannot hope for significant or permanent improvement from this approach alone. Moreover since the physical stigmata of the disorder may have generated increased sympathy and attention or may have provided a mean by which the patient was able to avoid social contacts or responsibilities, their removal, without improvement in the basic cause may result in heightened anxiety.

An effective approach to the patient exhibiting this syndrome requires, a careful explanation as to the means by which emotional stimuli can result in the release of chemical mediators. Which in term, result in excessive salt and water retention and finally reassurance that 
the actual weight gains can be corrected and prevented by appropriate medical, therapy. With time, the syndrome tends to run out its i6urse in most instances. And this fact can provide additional optimism. It is important for a patient to understand that excessive diuretic therapy may initiate an entirely new category of symptoms, such as fatigue, muscular weakness and postural hypotension.

For most patients, a period of hospitalization initially is essential. This will provide an opportunity for caring out diagnostic tests designed to exclude organic disease, for psychiatric consultation, for a demonstration of the importance and significance monitoring morning and evening changes in weight, and for a more favorable situation in which to initiate a therapeutic salt losing program. Bed rest and a low calorie-diet measurably improve the effectiveness of reduced sodium intake and diuretic therapy.

\section{Dietary Control-Calorie intake}

Since obesity increases the tendency to retain fluid, the calorie intake should be restricted until ideal weight has been attained.

\section{Sodium chloride intake}

A diet not to exceed 3 to $5 \mathrm{gm}$ of sodium chloride is recommended for most patients since this, for practical purposes approximates the lower level to which patients can adjust their diet at home. In very severe and resistant cases, the sodium chloride level may have to be reduced initially to $1 \mathrm{gm}$ or less.

\section{Fluid intake}

There is no need to restrict water or liquid intake unlesshypo-osmolality of the serum or hyponatraemia exists.

\section{Potassium intake}

The ingestion of foods high in potassium should be encouraged especially 'those which are also low in sodium, such as bananas. Supplementary potassium may be administered to patients with significant depletion but, when spironolactone is used regularly and continuously, a potassium is usually not required.

\section{Role of Diuretics}

Diuretics may be initially useful, but may loose their effectiveness with' continuous adpinistration2T. Many patients find that diuretics are required only intermittently to control exacerbation of fluid retention, such as premenstrually ${ }^{2}$. In fact all patients should initially be treated in this way. Persistent discontinuation of diuretics paradoxically leads to diuretics in diuretic induced oedema ${ }^{27}$.

Diuretics are most effective in non-obese fluid retaining women with no history of weight gain or severe affective illness. As weight increases or psychiatric illness becomes more severe, they become less effective. This may lead to consumption of increasing doses of diuretics (especially loop diuretics) with the consequent risk of electrolyte depletion. Diuretics are usually ineffective in obese fluid retaining patients or in patients with severe psychiatric disorder regardless of weight ${ }^{25}$

A thiazide diuretic with either a potassium supplement or a potassium sparing diuretics should be prescribed if required. Loops diuretics should be avoided and spironolactone is no longer recommended for the treatment of fluid retention syndrome by the committee on Safety of Medicines. If fluid retention ii due to associated with marked increase in adrenal secretory rate of aldosterone, then sustained diuresis can be induced by spironolactone, an aldosterone antagonist, was repcirted by Greenough et al. ${ }^{3}$

\section{Role of Angiotensin Converting Enzyme inhibitor (ACE inhibitor)}

The reductions in urine volume and sodium excretion on standing were attenuated by the administration of captopril to patients with fluid retention syndrome ${ }^{28}$. Captopril, induces urinary excretion of water and electrolytes in several ways. First, it is considered that the administration of captopril increases the urine volume and sodium excretion by inhibiting aldosterone production through blocking argiotensin II formation. Captopril significantly inhibited the increase in plasma aldosterone in upright position in five patients, but in the other 3 patients, captopril increased the sodium excretion without reduction of plasma 
Iavels of aldosterone. The finding that potassium excretion increased slightly after

captopril administration in some patients may suggest that inhibition of aldosterone. Production by captopril, was incomplete (Hall et al, 19772). Therefore, it is considered that the increase in urinary excretion of sodium by captopril is not necessarily due to the reduction in aldosterone concentration. Second, there have been many report $\$$ on the intrarenal action of angiotensin-Il which is considered to reduce the glomerular filtration rate and enhance the sodium reabsorption at the proximal tubule, causing antidiuresis and antinatriuses [Kimbrough et al, 197730; Ploth and Navar, 197931; Levens et al 198132]. It is suggested therefore, that the increased urine volume and sodium excretion. Afteradministration of captopril in patients with idiopathic oededra may be athibuted to inhibition of the intrarenal effect of the reninangiotesin system by captopril. Third, it is reported that urinary kallikrein and kinin excretion are significantly lower in patients with idiopathic oedema (Shimamoto et aI, 198033). Therefore the possibility cannot be excluded that accumulation of bradykinin secondary to kininase-Il inhibition by captopril may influence the urinary excretion of sodium [Carreteroa nd Scicli, 197834M; c Caa et al, 197835]. Study demonstrated the presence of hyperresponsiveness of the renin-angiotensin - aldosterone system to an upright posture in the patient with FRS. This observation is compatible with the fact that captopril exerted a remarkable diuretic effect in these patients. The recent study in which the chronic effect of captopril in diurnal weight difference $=$ and urinary sodium and water excretion was studied in patients with idiopathic oedema (Docci et al, 198336), also suggested that captopril iseffective for idiopathic oedema.

The Role of Sympathomimetic Amines on FRS In an attempt to constrict excessive dilated precapillary sphincters, which have hypothesised to be the cause of orthostatic oedema. Since 195637, sympathomimetic amines, especially dextroamphetamine have been administered. Many patients showed a gratifying reduction in oedema and a reduction in weight gain from morning to evening that no conventional diuretic therapy or even spironolactone could accomplish. In 1962, Greenough et $\mathrm{a}^{13}$ reported striking natriuretic effects of ephidrine in a dose of 200-300 mglday, phenylephrine in a dose of 300-500 mg/day and hydroxyamphetamine $100-500 \mathrm{~m} /$ day, given separately to a patients with FRS, as forms of therapy for her associated with hypotension. Again the episodes of sodium retention and oedema formation were demonstrated to be associated with marked increase in the adrenal secretary rate of aldosterone as a consequent of decreased circulation to kidney. The beneficial effect of sympathomimetic drugs are viewed as a consequence of a direct or indirect action to improve the renal circulation, leading to suppression of the generation of an aldosterone stimulating factor probably angiotensin ${ }^{37}$. Since then the mechanism of natriurietic action of dextroamphetamine has been analyzed by Speller and Streeten ${ }^{39}$, ho found that the natriuresis was associated with reduction of aldosterone excretion in normal subjects and in patients with idiopathic oedema. Moreover, no natriuretic effect of dextroamphetamine could be found in patients with primary adrenal insufficiency, confirming that this action was mediated through an effect on adrenal function. A significant negative correlation was found between the excretion of sodium and aldosterone during dextroamphetaine therapy. Thus these observations were in good agreement with Greenough et $\mathrm{al}^{37}$ that sympathomimetic amines did reduce aldosterone secretion and promoted natriuresis by this mechanism.

\section{External Compression}

Judging from the experimental demonstration of the benefit conferred by external pressure with an inflated G -suit or through Ace bandaged slightly wrappeda round the legs and thighs, $t$ he use of elastics tockings would be expected to be of great therapeutic value in these patients.

\section{Monitoring of weight}

A careful record of the changes in daily weight, recorded both in the morning and the evening 
constitutes Avery important aspect of the therapeutic program .T therapy can be accurately monitored by this relatively simple device and if plotted on graph paper, will provide an excellent basis for discussion between patient and physician. Will a record such a this, the physician can be confident in predicting the changes in the therapeutic progress which will be' required and patient will be reassured by the information which the chart conveys ${ }^{4}$.

\section{Psychiatric consultation}

With the help of psychiatric consultant, the physician will be in a strong position to understand the needs of his patient, and the most effective way in which these can be met.

Swimming and muscular exercise

Some patients with FRS have learned by experience supported by body weight 4ecords that a program of swimming daily helpful to them. The recumbent posture in which the subject swims the cooling effect of the water, and perhaps the external pressure of the water when the subject is not might all have beneficial effects.

Moreover, there is evidence from a paper written in $1931 .{ }^{41}$ That the legs's well less in the upright posture innormal subjects who are in good physical training than in those who are not. Perhaps the commonness of idiopathic oedema in the present era is the consequence of the modern sedentary life.

\section{References}

1. Thorn. GW: Approach to the patient with 'idiopathic oedema' or 'periodic swelling'. J Am Med Ass 1968: 206: 333-338.

2. Streeten DHP: Idiopathic oedema: Pathogenesis, Clinical features and Treatment: Metabolism, 1978: 27: 353-383.

3. Dunnigan MG: Management of fluid retention syndrome in women, Hospital update: 1990: 653662.

4. Thorn. GW; Cyclical oedema. The Am. J. Med. $1968: 23: 507-509$.

5. Kuchel O, Horky K, Gregorova I, Marek J, Kopecka $\mathrm{J}$, Kobilkova $\mathrm{J}$ : Inappropriate response to upright posture: A precipitating factor in the pathogenesis of idiopathic oedema. Ann Intern Med 1970: 73: 245-252.

6. Smit HW. Physiology of the renal circulation. London: Harvey; Lect, 1940: 35: p.166.222.
7. Gordon RD, Kuchel O, Liddle GW, et al: Role of symathetic nervous system in regulating renin and aldosterone production in man. J. Clin. Invest. 1967: 46: 599-605.

8. Balikian HM, Brodie AH, Dale SL, et al: Effect of posture on metabolic clearence rate, plasma concentration and blood production rate of aldosterone in man. J Clin Endocr 1968: 28: 16301640 .

9. DHP, Speller PJ: The role of aldosterone and vasopressin in the postural changes in renal excretion in normal subjects and patients with idiopathic oedema. Metabolism. 1966: 15: 53-64.

10. Fisher DA, Morris MD: Idiopathic oedema and hyperaldosteronuria: Postural venous Pooling. Paediatrics 1965: 35: 413-424.

11. Edwards OM, Bayliss RIS: Idiopathic oedema of woman. Q J Med 1976: 45: 125-144.

12. Kline RL, Scott JB, Haddy FJ, et al: Mechanism of oedema formation in. canine fore limbs by locally administered bradykinin-Am J Physiol, 1973: 225: $1051-6$.

13. Streeten DHP, Kerr LP, Kerr CB, et al: Hype rbradykininism: a New orthostatic syndrome. Lancet 1972; 2: 1048-53.

14. Clarkson B, Thompson D, Horwith $\mathrm{M}$, et al: Cyclical oedema and shock due to incresed capillary permeability. Am J Med 1960; 29: 193216.

15. Bougas JC Flood, B Little, J F Tait, SAS Tait, R Underwood, IN Baulien, EE, P Robel eds. Aldosterone, Blackwell Sci. Publ. Oxford, 1964, p-25.

16. Gill JR, Waldmann TA, Bartter FC: Idiopathic oedema. The occurrence of hypoalbuminemia and abnormal albumin metabolism in woman with unexplained oedema. Am J Med 1972; 52: 144445.

17. Sims EAH, Mackay BR, Shirai T: The relation of capillary angiopathy and diabetes mellitus to idiopathic oedema. Ann Intern Med 1956: 65: 972978.

18. Streeten DHP, Dalakos TG, Souma M, et al: Studies of the pathogenesis of idiopathic oedema. The role of postural changes in plasma volume, plasma renin activity, aldosterone secretion rate and glomerular filtration rate in the retention of sodium and water. Clin Sci Mol Med 1973; 45: 347-73.

19. Coleman M, Horwith M, Brown JL: idiopathic oedema. Studies demonstrationg protein-leaking angiopathy. Am. J. Med. 1970; 49: 106-13.

20. MacGregor GA, Tasker PRW, Dewardener HE : Diuretic-induced oedema . Lancet, 1975; 1: 48992. 
21. Horky K, Kuchel O: Compulsive salt intake and oedema. Lancet; 1967; 261-262.

22. Thorn GW, Nelson KR and Thorn DW. A study of the mechanism of oedema associated with menstruation. Endocrinology. 1938; 22: 155.

23. Arnoldsson H, Belin L, Hallberg L', Helander E, Lindholm B, wastling $\mathrm{H}$ : Hereditary periodic Oedema. Acta Medica Scand. 1967; 181: 115-24.

24. Pelosi AJ, Sykes RA, Lough JRM, Muir WJ, Duunningan MB: A Psychiatric study of idiopathic Oedema. The Lancet 1986; 1: 999-1001.

25. Dunnigan MG: The recognition and management of fluid retention (idiopathic or cyclical oedema) and Pre-menstrual syndrome. InMcNaughton $\mathrm{C}$, Ed. Medical gynaecology, Oxford: Blackwell scientific, 1985; p. 27-54.

26. McKendry JBR, Maclaren MC, Bloom GM. Idiopathic intermittent oedema of woman and interpersonal conflict. In: Psychosomatic medicine. Excerpta Med Int Congr Ser. 1996.

27. Isselbacher, Braunwald, Wilson, Martin Fauci, Kasper: Harrison's Principles of internal medicine. $13^{\text {th }}$ ed. 1994: p.186.

28. Greenough WB, Sonnenblick EH, Januszewicz et al: Correction of hyperaldosteronism and of massive fluid retention of undnown cause by sympathomimetic agents. Am J Med 1962: 33: 603-14.

29. Suzuki H, Fujimaki M, Nakane H, Saito I, Takeshita E, Saruta T. Effectiveness of angiotensin converting enzyme inhibitor, captropril (SQ $14,225)$. on orthostatic sodium and water retention in patients with idiopathic oedema. Nephrone 1985; 39: 244-9.

30. Hall JE, Guyton AC, Trippodo NC, Lohmeier TE, Ma Caa RE, Cowley AW : Intrarenal control of electrolykte excretion by angiotensin-II. Am J Physiol 1977; 332: 538 -544.
31. Kimbrough HM, Vanghan ED, Carey RM, Ayers CR: Effect of intrarenal angiotensin-II blockade on renal function in conscious dogs. Circulation Res 1977; 40: 174-8.

32. Ploth DW. Navar LG: Intrarenal effects of the renin angiotensin system. Fed Proc 1979; 38: 2280-5.

33. Levens NR, Peach MJ, Carey, RM. Role of intrarenal renin angiotensin system in the control of renal function. Circulation. Res 1981; 48: 157167.

34. Shimamoto K, Tanaka S, Ando T, Naka OT. Nakahashi Y, Miyahara M: Role of endocrinological factors, in the pathogenesis of idiopathic oedema. Tohoku J Exp Med 1980: 130: 71-8.

35. Carretero OA, Scicli AG: Renal Kalikrein: its localisation and possible role in renal function. Fed Proc 1978: 35: 194-8.

36. Mc Caa RE, Hall JE, Mc Caa CS: The effect of angiotensin-I converting enzyme inhibitors on arterial blood pressure and urinary sodium excretion. Circulation Res 978; 1, 43 suppl; 32-9.

37. Docci D. Turci F, Salvi G: Therapeutic response of idiopathic oedema to captopril. Nephron 1983; 34: $198-200$.

38. Streeten DHP, Conn JW: Studies on the parthogenesis of idiopathic oedema. [abstract] J Lab Clin Med 1959: 54: 949-50

39. Speller PJ, streeten DHP: Mechanism of the diuretic action of D-amphetamine. Metabolism, 1964; 13: 453-65.

40. Shaw RA, Kryston LJ, Fleischmajer R, Kashatus WC, Segal BL, Gambesia JM Mills LC: The Rationale for tretment of idiopathic oedema. [abstract] Am J Cardiol 1968; 21: 115

41. Waterfield RL: The effect of posture on the volume of the leg. J Physiol 1931; 72: 121-31. 